\title{
American Journal of History and Culture
}

(ISSN:2637-4919)

\section{Regional cultural expression of cultural architecture-Take the design works of Yichang History and Culture Theme Exhibition Hall as an example}

\author{
Ye Wu ${ }^{1 *}$, Xiao Shao ${ }^{2}$, Guozhu Chen ${ }^{3}$ \\ ${ }^{1}$ College of Civil Engineering \& Architecture, China Three Gorges University, Yichang, 443002, China. \\ ${ }^{2}$ College of Medicine, China Three Gorges University, Yichang, 443002, China. \\ ${ }^{3}$ College of Hydraulic \& Environmental Engineering, China Three Gorges University, Yichang, 443002, China.
}

\section{ABSTRACT}

Cultural buildings have distinct regional characteristics. How

*Correspondence to Author:

to make them have regional characteristics is an important $\mathrm{Ye} \mathrm{Wu}$

point to judge the success or failure of a cultural building College of Civil Engineering \& Archdesign. Take Yichang City's cultural architecture design as an itecture, China Three Gorges Univexample to explore how regional cultural characteristics are ersity, Yichang, 443002, China.

reflected in the architecture. From the aspects of humanities and natural environment, we provide an in-depth analysis of the cultural design of local characteristics, and discuss the specific application of different factors in the design of stylistic architecture.

How to cite this article:

Ye Wu, Xiao Shao, Guozhu Chen. Regional cultural expression of cultural architecture-Take the design

Keywords: Cultural architecture; Regional culture; Featured themes

works of Yichang History and Culture Theme Exhibition Hall as an example. American Journal of History and Culture, 2019,2:12

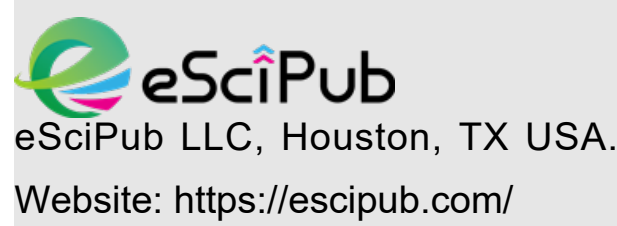




\section{Introduction:}

With the advancement of technology and the development of the times, cultural architecture is more and more representative of the image of a city. Due to the advent of the information age, more and more cities lack their own particularities. Therefore, how to extract and carry forward the regional characteristics, combined with the characteristics of the regional environment to design a building with local architectural characteristics has become the focus of cultural architectural design, it should also be the direction of the peers.

\section{Project background}

The project is located in Yichang City, Hubei Province, and Yichang City is known as a tourist city. There are 747 tourist attractions in the city, including 4 national 5A scenic spots, and the tourism resources can be described as unique. The local humanities have a deep roots and are the birthplace of Bachu culture. There are historical celebrities such as Qu Yuan and
Wang Zhaojun. Yichang belongs to the hilly area. The terrain is high and low, and the human atmosphere is very strong. Therefore, designing a historical exhibition hall in the area naturally needs to be unique and representative.

The project belongs to the old part of Yichang City (Fig. 1), adjacent to the main road of Huancheng South Road, and the other side is adjacent to Nanzheng Down Street and Bao pu han Street. The traffic conditions are very convenient. It is located inside the old town and surrounded by old buildings. Therefore, the surrounding itself has a strong historical heritage, which is conducive to creating an image of the city's image. The total land area of the base is 4,350 square meters and the construction area is 4,120 square meters. The main structure of the building is frame structure. The main purpose of this project design is to design a representative exhibition hall of the city in the old part of Yichang city culture.

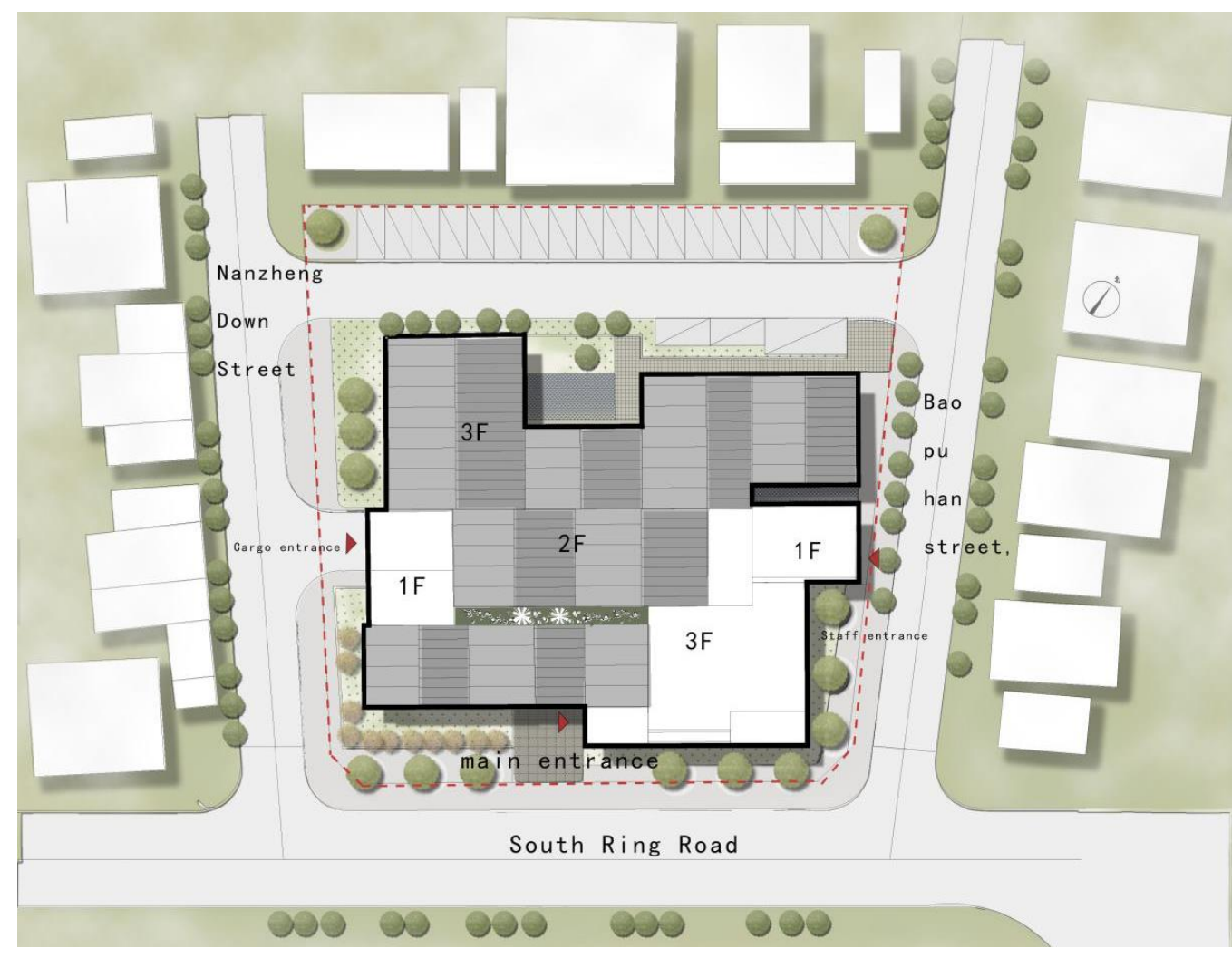

(Fig.1 general layout)

AJHC: https://escipub.com/american-journal-of-history-and-culture/ 


\section{Design idea}

\subsection{Architectural design}

Yichang City has a humid weather and a developed water system. Therefore, the buildings in this area are mostly in the form of sloping roofs to facilitate drainage. According to our research, we know that the surrounding buildings are mostly multi-storey buildings, which have the characteristics of typical Huizhou architecture. Therefore, we combine the architecture itself with the local architectural style to form a sloping roof. However, in order to reflect the characteristics of the building as a historical

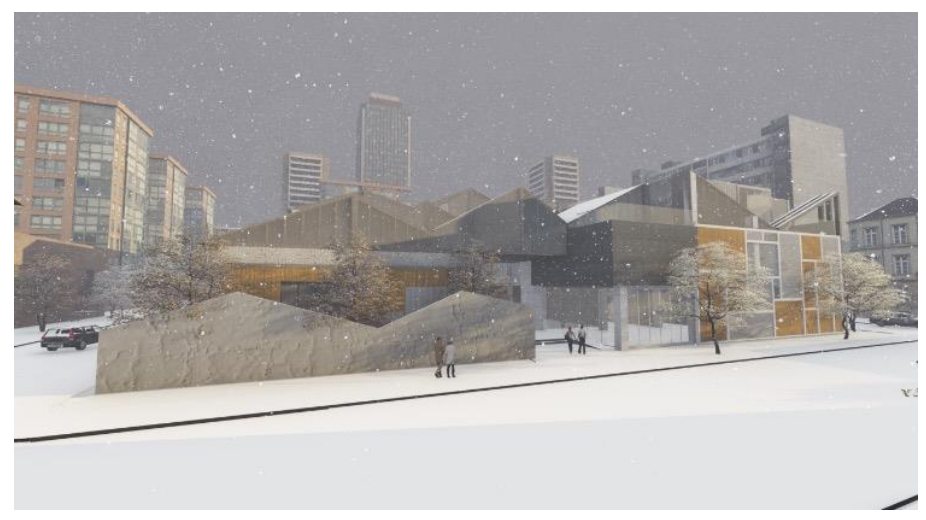

(Figure 2 view of building people)

\subsection{Bulk generation logic}

In the logic of block generation (Fig. 4), we have the following ideas: First, echo the texture of some of the buildings in the old town, divide the building from a single block into several different geometric blocks that bite each other while surrounding it. The courtyard texture of the building is integrated into the interior, and the different elements are integrated into the same building. This has a comprehensive experience that creates a considerable and interesting spatial experience. After forming the basic body texture, we incorporate the traditional and modern architectural representations exhibition hall, only the roof elements of the slope are obviously too pale and weak. Therefore, we consider the design of the building form as a sloping roof with a flat roof (Figures 2 and 3 ), which creates a sense of collision between modernity and tradition, echoing its own theme. We combine the rectangular elements of modern architecture into the façade design, which symbolizes that the sloping roof elements of traditional architecture and the rectangular elements symbolizing modern architecture collide with each other, echoing itself as the theme of the historical museum.

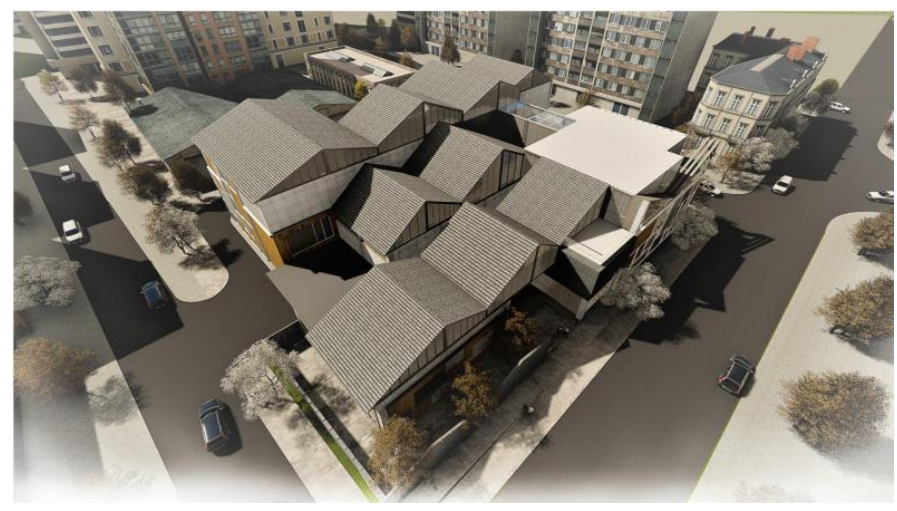

(Figure 3 Architectural aerial view)

of the triangles and rectangular shapes represented by the sloping roof into the façade design, thus forming a sense of rhythm of collision. At the same time, in order to echo Yichang itself belongs to the mountainous city, the surrounding landscape resources are good, the mountains are stretched, and the water body is characterized by the squatting. We design the roof shape into a form of a long roof, so that the distance will give people a feeling of stretching. It seems that a mountain peak collides with each other. This will make the building itself have the characteristics of Yichang itself. 


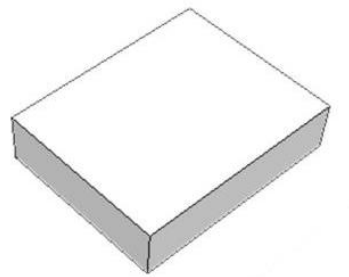

According to the backoff requirement, the approximate shape is obtained.

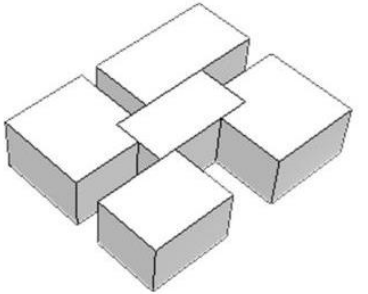

Respond to the texture of the surrounding buildings.

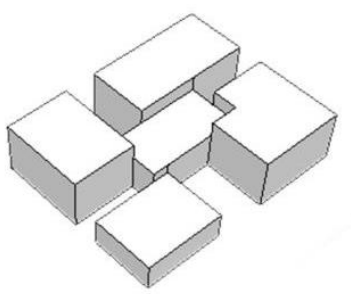

Building height generation

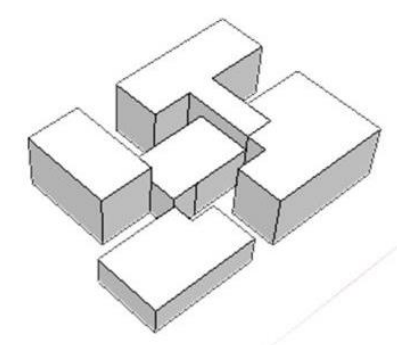

Node space integration

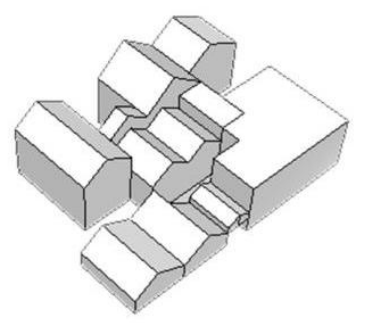

Model generation

(Figure 4 Body block analysis)

\subsection{Fun space design}

An exhibition building must have a collision of large and small spaces. For example, the height of the exhibition hall will be higher than the height of the office space in the building, which is convenient for forming a fun space such as a mezzanine space. So in the exhibition building we also set up a lot of interesting space parts. First of all, we consider that the simple sloping roof and the flat roof colliding form are inevitably monotonous, and it is interesting to construct the space of the building itself to create a gray space formed by the blending of indoor and outdoor space. Therefore, we consider combining the library and the entrance space to design a fun space (Figure 5).Since the library function itself requires a separate streamline function, and because of the existence of the ladder itself, there is a need for a separate space to accommodate the height. Therefore, we combine the functions of this part with the main entrance function to form a separate body shape. Readers can view the view from the window through the large floor-to-ceiling win- dows. They can also walk directly to the reading room overhead of the main entrance of the building through the steps of the reading room, so that people can visually see the activities of people outside the building while reading inside the building. Forming a line of sight communication and a rich sense of space, so that the library has a rich space, it is not only a space for reading, but also a space with a combination of viewing and leisure.

We put light and ventilation on the patio part of the main entrance of the building, which creates a good view of the landscape and forms a natural separation between the main entrance space and the office space to avoid the problem of streamline insertion (Figure 7). When people enter the building, they can see the beautiful atrium space, which can bring a good space experience to the audience, and naturally create a feeling of difference from the outside space, giving them a feeling of having officially entered the viewing building. And we adhere to the purpose of creating a good space language with architecture. Around the feature 
that Yichang as a landscape tourism city, we combine the landscape space with the architecture itself to form a good architectural form.. At the same time, we also designed a large glass curtain wall to connect the outdoor landscape to the interior of the building (Figure 6). This will create a sense of indoor diplomacy for tourists. People may see the beautiful landscape as they look up and form a good space experience.

Around the main entrance and exit of the building, we set up the atrium landscape (Fig. 8), so that when people enter and leave the building, they form a sense of sequence. When people enter the building, they have a good feeling of space experience. In this way, people naturally

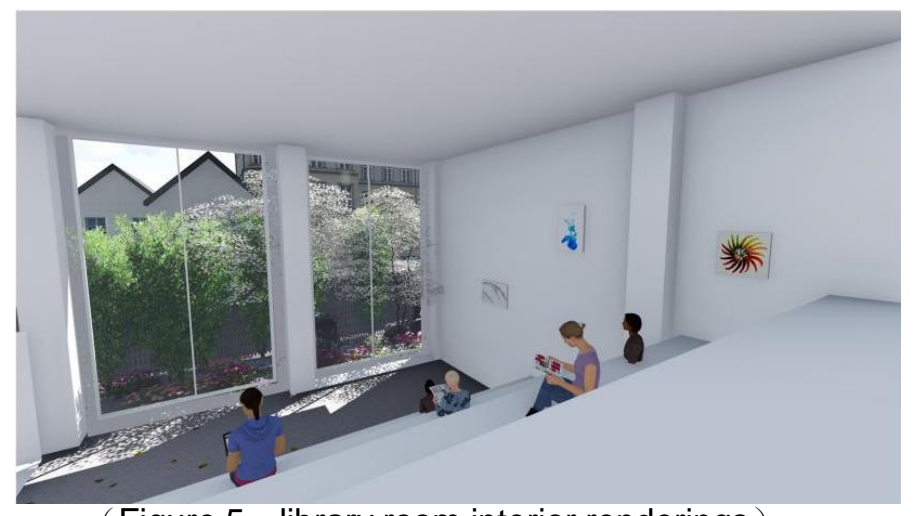

(Figure 5 library room interior renderings)

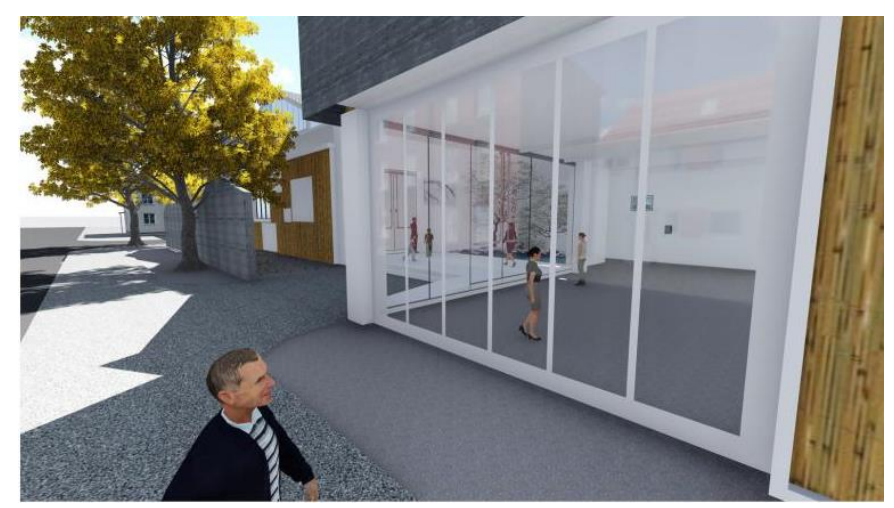

(Figure 7 Building main entrance space)

\subsection{Enclosed space design}

Buildings need some space between public and private spaces, which creates an interesting grey space for people to rest and play. In have an intuitive feeling of entering the building and leaving the building. At the same time, the landscape level thus formed can also penetrate into the interior of the building. People inside can naturally see the outer landscape level and form a rich spatial experience.

In the export section of the building, we have created a transparent space where people can have tea breaks, chat with each other and other leisure activities. At the same time, they can also enter the exhibition hall from the side, or enjoy the outside view through the large floorto-ceiling windows. In this way, the separation of the indoor and outdoor spaces can be weakened, giving people a feeling of being close to nature.

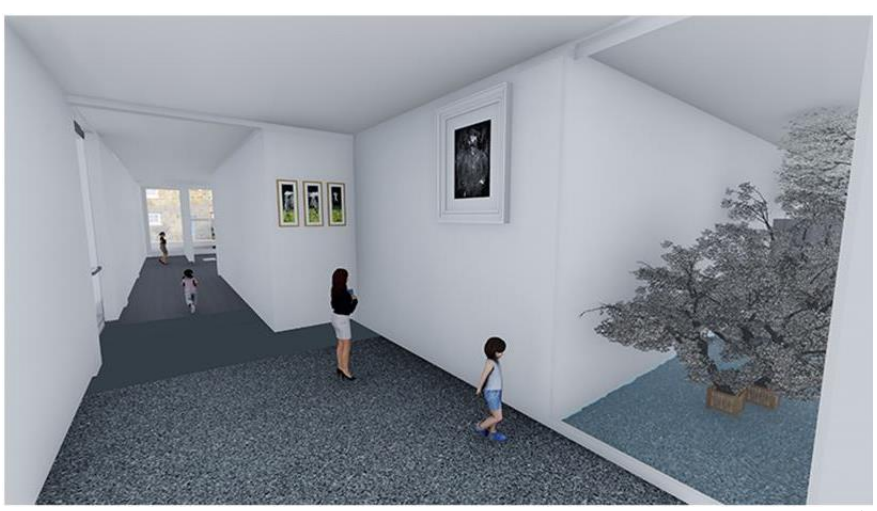

(Figure 6 Indoor and outdoor space blending place)

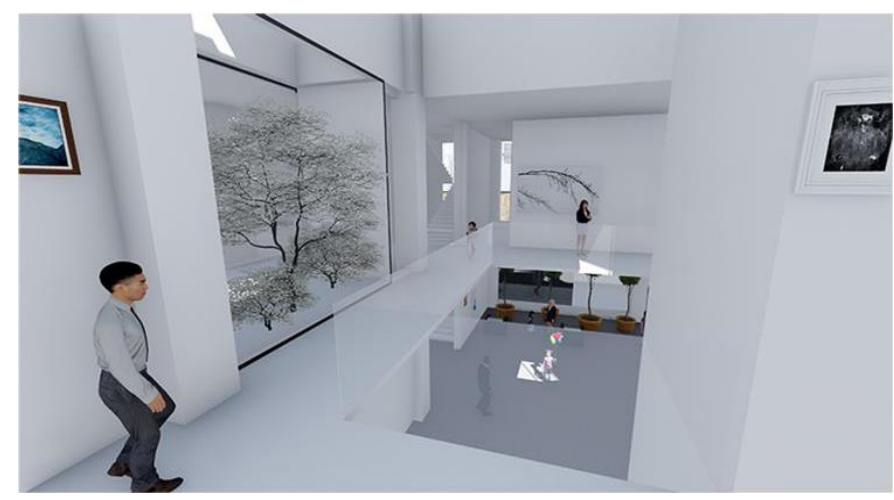

(Figure 8 Atrium space)

the architectural design of this exhibition hall, we have conveniently designed the building in such a language form. In order to echo the form of the sloping roof of the building itself, we de- 
sign the wall in the part that needs to design the wall to form a shape of the wall that echoes the shape of the roof, so that there is echo and fusion. In order to weaken the contrast and contrast in the flat roof part, we use the form of the frame to continue the collision of the fold lines of the side roof, so that the different volumes are perfectly integrated.

In addition to the continuous tortuous sloping roof form on the upper part of the wall, we also used this idea to form a frame in the lower part of the wall (Fig. 10). This enhances the sense of penetration of the space, giving people a sense of step by step, giving people a feeling of playing in the classical Chinese courtyard. Walking through the wall, some parts blocked the noisy field of view outside, forming a good feeling of internal space, and some parts penetrated each other through the opening and the view of the outside old city. When people came out inside the historical exhibition hall they can see the scenes of life around the Yichang Old Street District, and this is also the best historical space experience.

Visitors also have a similar wall opening and closing pattern when walking to the back of the inner courtyard (Fig. 9), which naturally forms the feeling of a picture frame. We can see the interior of the courtyard when we are outside, and people inside the courtyard can also see the visitors outside the courtyard through the opening. This creates a spatial fusion between each other (Figure 10).And when people actually walk in from the gap, they will find that the interior is another landscape. Not only the courtyards, landscapes, flowers and plants, but also visitors to the public activities of the building through the large floor-to-ceiling windows of the adjacent buildings. This invisibly breaks the sense of closure of space and forms a blend of indoor and outdoor spaces.

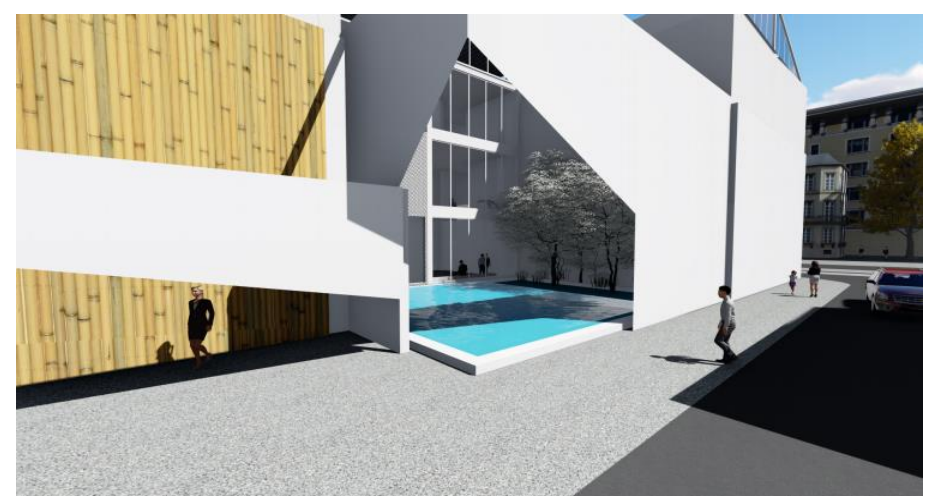

(Figure 9 Infiltration of space inside and outside the courtyard)

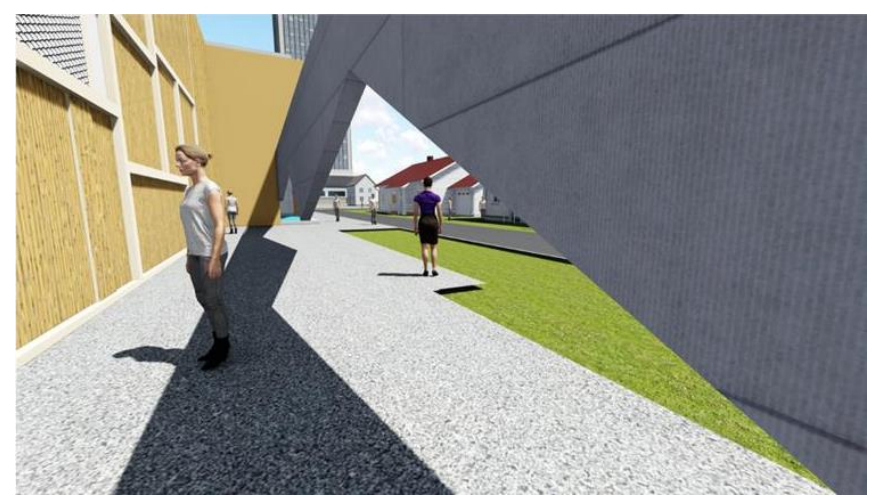

(Figure 10 Space penetration)

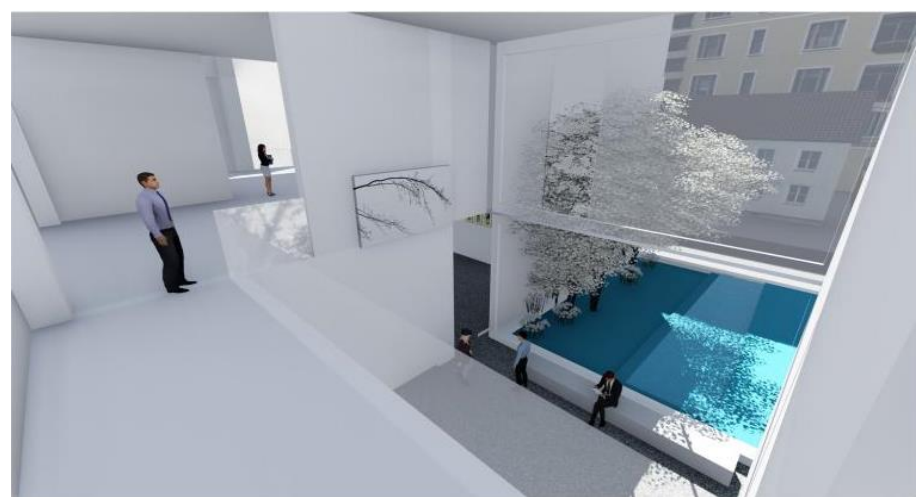

(Figure 10 Large part of the exit section)

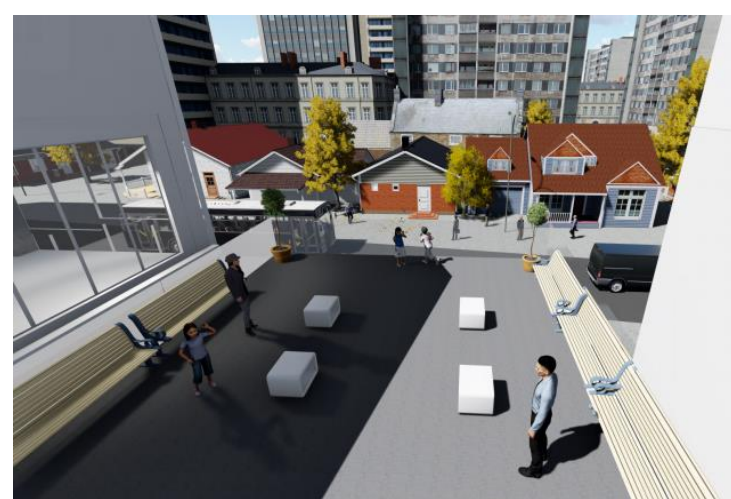

(Figure 11 Outdoor exhibition space)

AJHC: https://escipub.com/american-journal-of-history-and-culture/ 


\subsection{Fun exhibition space design}

In the exhibition building, the existence of the exhibition space is not limited to the indoor enclosed space. More often, the exhibition space can be combined with some outdoor space design to form a fun. In this design, the author designed some of the roof space as an outdoor exhibition site (Figure 11). After the audience has finished playing, they will naturally rest on the open roof terrace. Since the building itself is located inside the old city, there are more historical buildings around, so the audience can intuitively feel the historical customs of Yichang. In such a space, it is more suitable to arrange outdoor exhibition space. In addition to visually recognizing the legacy of Yichang's historical buildings, visitors can also visit the exhibits, so that the space combined with the exhibition space and the rest space will be very rich and interesting. It not only enriches the single exhibition space, but also brings more possibilities to the rest space.

\section{Architectural modeling design}

Most of the time we can intuitively feel the functional form of the building itself from a building's exterior, such as a library building that tends to be culturally pleasing; and a commercial complex that appears to be commercial. Therefore, when designing a historical exhibition hall, we hope that it can display the historical characteristics and humanistic characteristics of a city. Therefore, in terms of design, we follow the customs of the place and design a building that can display local humanities and customs and humanities.

In the façade design we also used a combination of rectangular elements and triangular elements. We split the array of rectangular elements into a form of cell division, in order to compare the scattered patterns of the buildings in the old city. Since the distribution layout of the previous buildings was naturally formed and there was no strong planning control, the layout of the general plan often showed scattered distribution. Therefore, the shape of the array of rectangular elements can reflect the characteristics of the scattered layout of the local architecture. This helped to express the characteristics of the historical exhibition hall.

\section{Conclusion}

Exhibition buildings often have strong subjectivity and representativeness. We can often lea$\mathrm{rn}$ about the characteristics of the city from its exhibition halls and museums in a city, including its customs, geographical conditions, humanities, etc. It is necessary to combine various aspects to consider how to design to make the building distinctive and meaningful. For example, the Suzhou Museum, which can be combined with regional culture and local customs, is considered to be a very successful design. The purpose of this paper is to give a design idea to the characteristics of the regional culture, customs, and even the topography of the exhibition hall through the author's own design case, aiming to give the peers some ideas. I believe that the idea of such a design should not be limited to the theme of an exhibition hall from a single shape, but more often it should be reflected in the rich spatial language and other aspects.

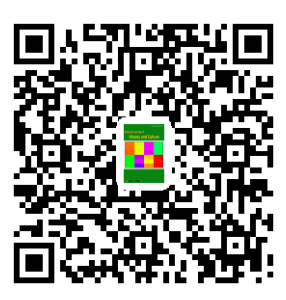

